\title{
BMJ Global Health Build on HIV investments for future pandemic preparedness
}

\author{
Chris Collins, ${ }^{1}$ Michael T Isbell, ${ }^{2}$ Jirair Ratevosian, ${ }^{3}$ Chris Beyrer, ${ }^{4}$ \\ Quarraisha Abdool Karim, ${ }^{5}$ Allan Maleche, ${ }^{6}$ Annette H Sohn ${ }^{7}$
}

To cite: Collins C, Isbell MT, Ratevosian J, et al. Build on HIV investments for future pandemic preparedness. BMJ Global Health 2021;6:e007980. doi:10.1136/ bmjgh-2021-007980

Handling editor Seye Abimbola

Received 11 November 2021 Accepted 20 November 2021

Check for updates

C Author(s) (or their employer(s)) 2021. Re-use permitted under CC BY-NC. No commercial re-use. See rights and permissions. Published by BMJ.

${ }^{1}$ Friends of the Global Fight Against AIDS, TB and Malaria, Washington, District of Columbia, USA

${ }^{2}$ Independent consultant, New York, New York, USA

${ }^{3}$ Department of Epidemiology, Johns Hopkins University, Baltimore, Maryland, USA ${ }^{4}$ Department of Epidemiology, Johns Hopkins Bloomberg Sch Publ Hlth, Baltimore, Maryland, USA

${ }^{5}$ Centre for the Aids Programme of Research in South Africa, Durban, KwaZulu-Natal, South Africa

${ }^{6}$ KELIN, Nairobi, Kenya

${ }^{7}$ TREAT Asia, amfAR, Bangkok, Thailand

Correspondence to

Chris Collins;

ccollins@theglobalfight.org
The COVID-19 pandemic has underscored the need for greater global investments in pandemic preparedness and response grounded in expanded research capacity and strengthened health systems. COVID-19 has demonstrated the importance and centrality of political and public health leadership, rapid innovation in diagnostics, therapeutics and vaccines and consistent communication with the public to build trust in services and uptake of new technologies. COVID-19 has also evidenced the need to strengthen global, national and local systems that work in concert against rampant health disparities and address structural inequalities. During the past 2 years, it has often been said that countries everywhere are only as safe as the weakest health system anywhere. It also is true that communities affected by a pandemic are only as safe as the most marginalised individuals among them.

The global response to HIV offers an established pathway to enhanced pandemic preparedness and response founded on strong, equitable and adaptable health systems. Major investments in the global HIV response over the past two decades have helped create a robust, multifaceted infrastructure for research, clinical care, commodity procurement and pricing, health information systems and community systems to address social and structural determinants of health. Born as a civil society movement in countries around the world, the HIV response has often been at the vanguard in establishing models for ensuring equitable access to rights-based services, advocating for direct community engagement, innovating in service delivery, expanding access to public health goods and optimising the strategic use of data.

With the world still in the grip of COVID-19 and policy-makers contemplating long-term approaches to pandemic preparedness and response, now is the time to consider how
Summary box

- The COVID-19 pandemic has underscored the need for greater global investments in pandemic preparedness and response grounded in expanded research capacity and strengthened health systems.

- The global response to HIV offers an established pathway to enhanced pandemic preparedness and response founded on strong, equitable and adaptable health systems

- With the world still in the grip of COVID-19 and policy-makers contemplating long-term approaches to pandemic preparedness and response, now is the time to consider how the HIV response both provides lessons in effective health service provision and how its infrastructure and core principles can be harnessed for pandemic preparedness and response.

- Using the HIV experience as a platform for robust preparedness and response, however, will demand that we heed the lessons that the fight against HIV has imparted.

- Policy-makers should be more intentional about identifying opportunities to 'build out' from HIV service platforms in ways that protect and advance progress on HIV and its core principles, including targeted services for the most vulnerable and support for community systems.

- With increased investment in HIV through national programmes, PEPFAR and the Global Fund, careful building out from the HIV response can simultaneously advance progress on HIV targets and rightsbased pandemic preparedness and response.

the HIV response both provides lessons in effective health service provision and how its infrastructure and core principles can be harnessed for pandemic preparedness and response. Using the HIV experience as a platform for robust pandemic preparedness and response, however, will demand that we heed the lessons that the fight against HIV has imparted.

First, it is important to consider the role the HIV response has played in COVID-19 thus far, a kind of 'test case' for its potential contributions. UNAIDS has documented the engagement of HIV-financed health workers, 
laboratory systems, surveillance sites, health clinics, procurement and supply chain systems, and communitybased organisations in providing COVID-19 services. ${ }^{1}$ PEPFAR has reported that strategic utilisation of PEPFAR-supported laboratories, surveillance capacities, healthcare workers, health management information systems and supply chains has helped countries respond to COVID-19. ${ }^{2}$

The Global Fund to Fight AIDS, Tuberculosis and Malaria pivoted early in the COVID-19 pandemic to tackle the new pandemic threat. ${ }^{3}$ It found that most low-income and middle-income countries responded to COVID-19 using the same infrastructure that was created to fight HIV, tuberculosis (TB) and malaria. ${ }^{4}$ It is not a surprise the Global Fund was able to react effectively when a new pandemic emerged, as more than a third of its investments are related to advancing health security. ${ }^{5}$

These reports are reinforced by interviews the authors did with key stakeholders in six low-income and middleincome countries in the first quarter of 2021. Interviewees detailed substantial contributions of national HIV platforms to COVID-19 responses. ${ }^{6}$ A particularly striking theme was the important role of civil society-including affected communities, networks of people living with HIV, key population groups and other organisationsin helping countries broaden the reach of COVID-19 testing, treatment and education.

In many ways, the HIV response departed from traditional approaches to addressing pandemics, offering a new, more inclusive and human rights-based paradigm for global health. These guiding principles uniquely position the HIV response as a resource in establishing effective, equitable and trusted pandemic preparedness and response. As the UNAIDS-Lancet Commission on Defeating AIDS-Advancing Global Health found, key characteristics of the HIV response distinguish it from many other health programmes including, 'the sustained leadership of civil society and people living with HIV, the multistakeholder nature of the response, the extraordinary degree of political leadership for the fight against HIV, the centrality of human rights, gender equity, and social justice to the response, and a commitment to global and local-level accountability and transparency'. ${ }^{7}$

These distinct qualities are invaluable in addressing specific priorities in building and sustaining health systems that are able to meet people's needs today and sufficiently agile to identify and respond to emerging disease threats. The HIV response and HIV movement did not invent principles such as 'access for all,' rightsbased programming, strategic use of data and participatory decision-making. Yet, in catalysing civil society, faith groups, researchers, donors, providers and senior political leaders to work towards common objectives, the HIV response has put these principles into action, and has fundamentally changed ambitions and expectations in global health.

But even as the HIV response has contributed to COVID-19 efforts, there is concern that decision-makers around the world will miss the opportunity to heed the lessons of the HIV response as they work to bring COVID-19 under control. In place of the international solidarity that characterised the history-making expansion of HIV treatment access, we have seen countries struggle to mount a serious response to blunt COVID19. The unconscionable disparities in COVID-19 vaccine uptake-as of early November 2021, 69\% of residents of the USA and Canada had received at least one vaccine does, compared with $9 \%$ in Africa ${ }^{8}$ - echo the access disparities seen for antiretroviral therapy at earlier stages of the HIV pandemic.

The emphasis on rights and access in the HIV response is an essential reference point for countries coping with COVID-19 and preparing for future pandemic threats. In addition to the stark variations in COVID-19 vaccine, therapeutic and prevention access among the world's regions, profound disparities have emerged within nearly all countries. COVID-19 efforts need to build on the HIV experience by addressing health disparities at every level, from global access to commodities, free access to services and non-discrimination in service delivery.

To take on board the lessons of the HIV response, national pandemic preparedness and response efforts must prioritise the engagement of communities-to build trust, inform effective programming and make services widely available. The central role of community members as advocates, providers and meaningful participants in public health decision making is fundamental in the HIV response. During COVID-19, we have seen communities in diverse settings swiftly adapt their work to provide COVID-19 services, displaying a unique ability to reach the most vulnerable populations, fight stigma and discrimination, respond to human rights violations, monitor services and push for equity in healthcare access.

It has been argued that HIV care infrastructure should be leveraged to provide broader integrated services, including for non-communicable diseases and new pandemic threats. ${ }^{9}$ We agree, but would emphasise that there remains a need for sustained and dedicated HIV services in many settings. HIV is still driven primarily through stigma, discrimination and social inequities, which we have battled for almost four decades. We have yet to guarantee the provision of safe and tailored services for key population groups across the world, who often must seek care outside of traditional health systems in order to meet their needs.

Efforts to advance stronger pandemic preparedness and response should build on synergies with the HIV response, suggesting several priorities for countries of all income levels. Though greater integration of health services is important in many settings, policy makers should also be more intentional about identifying opportunities to 'build out' from HIV service platforms in ways that protect and advance progress on HIV and its core principles, including targeted services for the most vulnerable and support for community systems. 
It will be impossible to heed the lessons of the HIV response for future pandemics unless all countries follow through on the commitments they have made to defeat HIV, TB and malaria. These infectious diseases remain major global health challenges, and new funding and focused efforts will be required to recover from the COVID-19 pandemic's effects in these and other disease areas. With increased investment in HIV through national programmes, PEPFAR and the Global Fund, careful building out from the HIV response can simultaneously advance progress on HIV targets and rightsbased pandemic preparedness and response.

In many ways, the global response to HIV presents a model for health services that seek to achieve universal access, spur innovation in service delivery, engage communities and serve the most vulnerable. The HIV response should serve as a global foundation for equitable and effective systems for health and better pandemic preparedness.

Twitter Chris Collins @ChrisCollinsGVA

Contributors All authors participated in discussing themes in the commentary, writing and editing of the piece.

Funding This study was funded by Friends of the Global Fight Against AIDS, TB and Malaria.

Competing interests None declared.

Patient consent for publication Not applicable.

Ethics approval This study does not involve human participants.

Provenance and peer review Not commissioned; internally peer reviewed.

Data availability statement No data are available.

Open access This is an open access article distributed in accordance with the Creative Commons Attribution Non Commercial (CC BY-NC 4.0) license, which permits others to distribute, remix, adapt, build upon this work non-commercially, and license their derivative works on different terms, provided the original work is properly cited, appropriate credit is given, any changes made indicated, and the use is non-commercial. See: http://creativecommons.org/licenses/by-nc/4.0/.

\section{REFERENCES}

1 UNAIDS, COVID-19 and HIV: 1 moment, 2 epidemics, 3 opportunities - how to seize the moment to learn, leverage and build a new way forward for everyone's health and rights, 2020, Geneva: Joint United Nations Program on HIV/AIDS. Available: https://www.unaids.org/ sites/default/files/media_asset/20200909_Lessons-HIV-COVID19.pdf

2 Achrekar A. Our global plan to fight HIV has been a strategic weapon against COVID, the Hill, 2021. Available: https://thehill.com/opinion/ healthcare/573056-our-global-plan-to-fight-hiv-has-been-a-strategicweapon-against-covid

3 Global fund to fight AIDS, tuberculosis and malaria, COVID-19 response mechanism, 2021. Available: https://www.theglobalfund. org/en/covid-19/response-mechanism/

4 Global fund to fight AIDS, tuberculosis and malaria, results report 2021, Geneva: global fund to fight AIDS, tuberculosis and malaria. Available: https://www.theglobalfund.org/media/11304/corporate_ 2021resultsreport_report_en.pdf

5 Boyce MR, Attal-Juncqua A, Lin J, et al. Global fund contributions to health security in ten countries, 2014-20: mapping synergies between vertical disease programmes and capacities for preventing, detecting, and responding to public health emergencies. Lancet Glob Health 2021;9:e181-8.

6 Beyrer C, Collins C, Isbell M, et al. Leveraging the HIV response for stronger health systems and pandemic preparedness, Washington D.C.: friends of the global fight against AIDS, tuberculosis and malaria, 2021. Available: https://www.theglobalfight.org/wp-content/ uploads/2021/10/Leveraging-the-HIV-Response-Nov-2021-1.pdf

7 Bekker L-G, Alleyne G, Baral S, et al. Advancing global health and strengthening the HIV response in the era of the sustainable development goals: the International AIDS Society-Lancet Commission. Lancet 2018;392:312-58.

8 World vaccination tracker, New York times. Available: https://www. nytimes.com/interactive/2021/world/covid-vaccinations-tracker.html [Accessed 09 Nov 2021].

9 Brault MA, Vermund SH, Aliyu MH, et al. Leveraging HIV care Infrastructures for integrated chronic disease and pandemic management in sub-Saharan Africa. Int $J$ Environ Res Public Health 2021;18:10751. 